ORIGINAL ARTICLE

\title{
Clinical assessment compared with breathalyser readings in the emergency room: concordance of ICD-10 Y90 and Y91 codes
}

\author{
C Cherpitel, J Bond, Y Ye, R Room, V Poznyak, J Rehm, M Peden
}

Emerg Med J 2005;22:689-695. doi: 10.1136/emj.2004.016865

See end of article for authors' affiliations

Correspondence to: Cheryl J Cherpitel, Alcohol Research Group, 2000 Hearst Avenue, Berkeley, CA 94709, USA; ccherpitel@arg.org

Accepted for publication 20 August 2004
Objectives: The purpose of this study was to analyse the validity of clinical assessment of alcohol intoxication (ICD-10 Y91) compared with estimated blood alcohol concentration (BAC) using a breath analyser (ICD-10 Y90) among patients in the emergency room (ER).

Methods: Representative samples of ER patients reporting within six hours of injury $(n=4798)$ from 12 countries comprising the WHO Collaborative Study on Alcohol and Injuries were breath analysed and assessed blindly for alcohol intoxication at the time of ER admission. Data were analysed using Kendall's Tau-B to measure concordance of clinical assessment and BAC, and meta analysis to determine heterogeneity of effect size.

Results: Raw agreement between the two measures was $86 \%$ (Tau-B 0.68), but was lower among those reporting drinking in the six hours prior to injury (raw agreement 39\%; Tau-B 0.32). No difference was found by gender or for timing of clinical assessment in relation to breath analysis. Patients positive for tolerance or dependence were more likely to be assessed as intoxicated at low levels of BAC. Estimates were homogeneous across countries only for females and for those negative for alcohol dependence. Conclusions: Clinical assessment is moderately concordant with level of BAC, but in those patients who have actually been drinking within the last six hours the concordance was much less, possibly because, in part, of a tendency on the part of clinicians to assign some level of intoxication to anyone who appeared to have been drinking.
A lcohol is among the most important risk factors globally as a cause of both disability and mortality, accounting for $4.0 \%$ of disability adjusted life years (DALYs) in the World Health Organization (WHO) estimates for 2000, and for higher proportions of DALYs both in developed (9.2\%) and in lower mortality developing countries $(6.2 \%) .{ }^{1}$ A substantial proportion of the disability and mortality attributable to alcohol is accounted for by injuries, both unintentional and intentional-32\% and $14 \%$ of injury deaths and $28 \%$ and $12 \%$ of DALYs, respectively-in the 2002 estimates. $^{2}$

\section{Emergence of $Y 90$ and $Y 91$ codes}

Although alcohol involvement in injuries has been demonstrated in numerous studies, data are primarily from special epidemiological studies rather than from ongoing recording systems. This deficiency in knowledge arises partly from the fact that alcohol's involvement has not routinely been recorded in coding injuries in mortality or morbidity surveillance systems. In the International Classification of Diseases, $9^{\text {th }}$ revision (ICD-9), ${ }^{3}$ as well as earlier versions, the primary circumstance in which alcohol could be coded was in relation to alcohol poisoning (E860.0 or E860.1, and 980.0, in ICD-9). In view of this, the 1984 WHO Informal Consultation on Proposals for the Classification of Mental Disorders and Psychosocial Factors in ICD-10 proposed that coding the degree of alcohol intoxication, and the nature of the evidence, should be encouraged "as an extra code in injuries". ${ }^{4}$ This suggestion was further developed in a 1987 proposal for ICD-10 coding from the US Alcohol, Drug and Mental Health Administration. ${ }^{5}$ In this version, two codes were proposed: one recording the blood alcohol content (BAC), and, when this was not available, a separate code recording the level of apparent intoxication. A modification of this was adopted in ICD-10 as the Y90 and Y91 codes, respectively. ${ }^{6}$ The subcodes of Y90 are defined by a series of nine blood alcohol levels: less than $20 \mathrm{mg} / 100 \mathrm{ml}$ (0.02); 20 $39 \mathrm{mg} / 100 \mathrm{ml} ; \quad 40-59 \mathrm{mg} / 100 \mathrm{ml} ; \quad 60-79 \mathrm{mg} / 100 \mathrm{ml} ; \quad 80-$ $99 \mathrm{mg} / 100 \mathrm{ml} ; \quad 100-119 \mathrm{mg} / 100 \mathrm{ml} ; \quad 120-199 \mathrm{mg} / 100 \mathrm{ml}$; $200-239 \mathrm{mg} / 100 \mathrm{ml}$; and $240 \mathrm{mg} / 100 \mathrm{ml}$ or more. There is also a code for the "presence of alcohol in blood, level not specified". Y91, which is intended to be used in the absence of a BAC measure, records an assessment of alcohol involvement determined by level of intoxication with four levels differentiated: Y91.0 (mild), Y91.1 (moderate), Y91.2 (severe), Y91.3 (very severe). Criteria for assessment at each level can be found in Appendix A. An additional code is used, Y91.9, to indicate alcohol involvement not otherwise specified.

\section{Relation of clinical assessment to blood alcohol concentration}

The provision of two alternative methods of recording the degree of alcohol intoxication raises the question of the level of agreement of the two measures. The concordance of these two measures might be expected to vary according to several factors:

- the extent of experience of the person making the assessment, and the opportunity to observe the individual's behaviour;

- the proximity in time of the BAC estimate to clinical assessment;

Abbreviations: BAC, blood alcohol concentration; DALY, disability adjusted life years; ER, emergency room; IA, Interviewer Assessment; ICD-9, International Classification of Diseases, $9^{\text {th }}$ revision; RAPS, Rapid Alcohol Problems Screen; WHO, World Health Organization 
- the extent of the subject's tolerance of alcohol, and

- cross-cultural variations in the behaviour of intoxicated individuals ${ }^{7}$ that might affect manifestations of intoxication.

Previous research on the relation of clinical assessment to BAC has been limited. A Finnish emergency room (ER) study, correlating BAC with physician assessment of three levels of intoxication and "no intoxication", found that among those assessed as not intoxicated, $14 \%$ had positive BACs (and half of those were above 0.10 ) whereas $12 \%$ of those assessed as heavily intoxicated had negative BACs. ${ }^{8}$ The physician assessment was found to distinguish better between any significant BAC (0.06 or above) and none than between different levels of positive BAC. A second Finnish ER study, in which assessment was carried out by a separate staff survey, found that among those assessed as not intoxicated, $11 \%$ had a positive BAC whereas $90 \%$ of those assessed as having some degree of intoxication had BACs of 0.06 and higher. ${ }^{\text {This }}$ line of work has since received relatively little attention.

Given the adoption of the Y90 and Y91 codes in ICD-10, testing the utility and convergent validity of the codes was among the main aims when the WHO Department of Mental Health and Substance Dependence, in collaboration with the WHO Violence and Injury Department, initiated the WHO Collaborative Study on Alcohol and Injuries in ERs of metropolitan hospitals in 12 countries. In addition to documenting the prevalence and role of alcohol involvement in injuries, and testing the concordance of clinical assessment with BAC, the Collaborative Study aimed to 1) test the feasibility of implementing Y91 coding for assessment and recording of alcohol intoxication in ERs in different societies; 2) develop and pilot materials to assist ER staff in assessing and coding the degree of alcohol intoxication; and 3) explore ways in which alcohol assessments/measurements could be worked into routine ER practice.

\section{METHODS}

Data from the WHO Collaborative Study on Alcohol and Injuries were collected in 2001-2002 from ERs in Argentina, Brazil, Belarus, Canada, China, Czech Republic, India, Mexico, Mozambique, New Zealand, South Africa, and Sweden. Study methodology across sites was similar to that used in previous ER studies. ${ }^{10}$ A probability sample of patients admitted for an injury within six hours of the event at each site was approached as soon as possible with informed consent to participate. Samples were drawn from ER admissions forms that reflected consecutive arrival of patients. The total sample across all sites of those 18 years and older was 5243 patients and represented a $91 \%$ completion rate. BAC estimates were obtained using a breath analyser and patients were given a 25 minute interviewer-administered standard questionnaire. A cohort of interviewers in each site was trained and supervised by study collaborators in their respective locations. A clinical assessment of intoxication made by an ER physician or nurse was also obtained, in most cases prior to the interviewer obtaining the $\mathrm{BAC}$ estimate. In instances where $\mathrm{BAC}$ was obtained first $(10 \%)$, the clinician was blind to the BAC estimate. In four sites (Belarus, Brazil, China, and India) an additional observational assessment of intoxication was obtained by a second interviewer (Interviewer Assessment) who had no knowledge of the breath alcohol estimate or of the clinical assessment of intoxication.

Physicians and/or nurses were trained by WHO study staff and site investigators using a module prepared by WHO, which included diagnostic criteria for intoxication, behavioural manifestations, description of clinical signs, testing for impairment, and other clinical conditions warranting a differential diagnosis. A sufficient number of clinicians were trained at each ER site to assure availability during the periods patients were sampled. The table used by clinicians to elicit clinical signs of intoxication and the observational assessment codes with accompanying descriptions, based on ICD-10 descriptions of alcohol intoxication at different levels, ${ }^{6}$ can be found in Appendix A. The observation assessment also recorded whether or not the clinician believed a substance other than alcohol might be involved.

Interviewers undertaking the Interviewer Assessment (IA) did not receive any special training in assessing for intoxication. The IA was included to test the ability to evaluate the level of alcohol intoxication without any prior training, using a form specifically designed for this purpose (see Appendix B).

BAC was analysed using the Alco-Sensor III intoximeter (Intoximeters Inc, St Louis, MO, USA), which provides estimates that are highly correlated with chemical analysis of blood. ${ }^{11}$

The interviewer-administered standard questionnaire was translated and back translated in each setting and included, among other items, whether the patient reported drinking within six hours prior to injury and a question related to tolerance: "During the past 12 months, have you found that you need to drink much more than before to get the same effect or that drinking your usual amount began to have less effect on you?" Patients were also asked four items comprising the Rapid Alcohol Problems Screen (RAPS4) as a measure of alcohol dependence. ${ }^{12}$ This instrument, developed in an ER population, is based on the optimal set of screening items from several instruments ${ }^{13}$ and has been found to perform as well or better than other screening instruments based on alcohol dependence criteria ${ }^{14}{ }^{15}$ in other ER populations. ${ }^{16-18}$ The RAPS4 asks the following:

During the past 12 months

1. Have you had a feeling of guilt or remorse after drinking?

2. Has a friend or a family member ever told you about things you said or did while you were drinking that you could not remember?

3. Have you failed to do what was normally expected of you because of drinking?

4. Do you sometimes take a drink in the morning when you first get up?

Patients giving positive responses on one or more items were considered to screen positive for alcohol dependence.

\section{Data analysis}

Primary data from each of the ER studies were cleaned and merged into a single data file. Data are analysed on the 4798 patients from whom both estimated BAC (Y90) and clinical assessment (Y91) data were obtained soon after ER admission ( $92 \%$ of the sample). To analyse the concordance of Y90 and Y91 codes the following mapping was used: BAC $\leqslant 0.059=$ no intoxication, $\mathrm{BAC} \geqslant 0.060-0.099=\mathrm{Y} 91.0$ (mild intoxication), BAC $\geqslant 0.100-0.199=$ Y91.1 (moderate intoxication), $\quad B A C \geqslant 0.200=Y 91.2 / Y 91.3 \quad$ (severe/very severe intoxication). This mapping was based on available published information about the rough correlation between BAC and levels of behavioural impairment ${ }^{19}{ }^{20}$ and descriptions of the Y90 and Y91 categories in the ICD-10. ${ }^{15}$

Kendall's Tau-B ${ }^{21}$ was used to measure the agreement of BAC categorisation with clinical assessment. Kendall's Tau-B measures concordance (analogous to positive correlation for rank order variables) or discordance (analogous to negative correlation) across all pairs of patients. Values of Tau-B range from -1 to +1 , where a value of -1 indicates perfect discordance of BAC and clinical assessment, a value of +1 indicates perfect concordance, and a value near zero indicates 
no association. ${ }^{21}$ Cohen's $\kappa$, the most commonly used index for measuring agreement between ordinal variables, has been found to depend heavily on the distribution of the variables analysed. ${ }^{22}$ Kendall's Tau-B has been found to perform better than other measures such as Kendall's Tau-C, Goodman and Kruskal's $\alpha$, and extensions of Spearman's $r^{23}$

Values of Tau-B using Y90 and Y91 codes were estimated both for the overall sample as well as for those who reported drinking within six hours prior to injury. Tau-B also was computed within each country by gender and by dependence as measured by the RAPS4. For those countries for which the IA was available, Tau-B additionally was computed between IA and the Y90 and Y91 codes separately. The estimated TauB for each ER along with its standard error was used to obtain an overall pooled estimate across study sites using meta-analytic techniques. Tests of heterogeneity of the values of Tau-B across studies were then carried out using the $Q$ statistic. $^{24}$ Results for both fixed and random effects are reported along with tests of homogeneity. ${ }^{25}$

\section{RESULTS}

Figure 1 shows the distribution of breathalyser readings by clinician assessment. Not included in this table are the 88 patients who were clinically assessed as alcohol involved but with no level of intoxication specified. Among those patients with a quantified level of intoxication assessed, $52(1.1 \%)$ had values of $\mathrm{BAC} \geqslant 0.10$ (moderate or severe intoxication) but were assessed as not intoxicated, whereas 24 patients $(0.5 \%)$ were negative on BAC but were clinically assessed as moderately or severely/very severely intoxicated. Possible reasons for these large discrepancies were examined. Among those patients with a BAC $\geqslant 0.10$, no difference was found on the RAPS4 between those clinically assessed as not intoxicated and those clinically assessed as moderately or severely/ very severely intoxicated; however, those assessed as not intoxicated were significantly less likely to be positive for tolerance $(4 \%)$ compared with those assessed as intoxicated $(21 \%)\left(\chi^{2}\right.$ test, $\left.p=0.005\right)$. Of the 24 patients clinically assessed as moderately or severely intoxicated but negative on BAC, the clinical assessment indicated that $50 \%$ may have other drug involvement compared with $6 \%$ of the remainder of the sample ( $\chi^{2}$ test, $\left.\mathrm{p}<0.001\right)$.

Overall, $84.6 \%$ of patients with a BAC $\geqslant 0.06$ were assessed as intoxicated, whereas $93.4 \%$ of those with a BAC $<0.06$ were assessed as not intoxicated (Yule's Y $=0.80$, Cramer's $\mathrm{V}=0.70$ ) (not shown). Table 1 shows the cross classification of clinical assessment by BAC. Nearly $82 \%$ of the sample had a BAC $<0.06$ and were clinically assessed as not intoxicated. In addition to Kendall's Tau-B (0.68), the footnote in Table 1 also provides several other measures of agreement commonly used, including a weighted Cohen's $\kappa(.57)$, Pearson's $r$ $(0.65)$, and Spearman's $r(0.70)$. These measures all indicate a

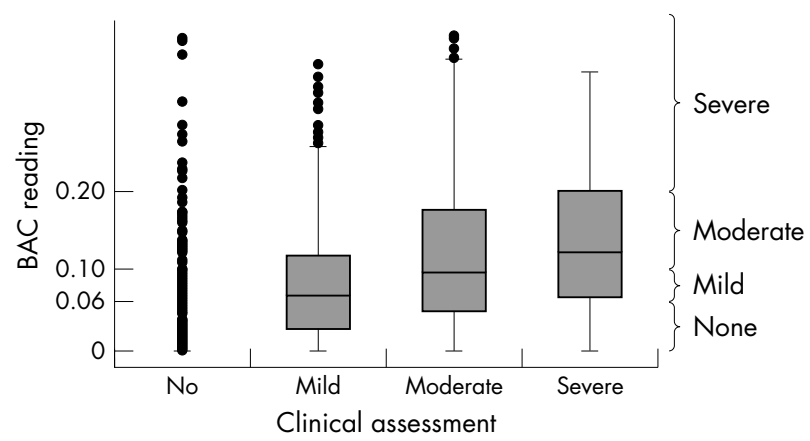

Figure 1 Distribution of blood alcohol concentration (BAC) reading by clinician's assessment on intoxication.
Table 1 Cross classification of clinical assessment (Y91) and blood alcohol concentration (BAC) (Y90) ( $n=4798)$

\begin{tabular}{|c|c|c|c|c|c|}
\hline \multirow[b]{2}{*}{ Y90 (BAC) } & \multicolumn{5}{|c|}{ Y91 clinical assessment } \\
\hline & None & Mild & Moderate & Severe & Total \\
\hline $0-0.059$ & 81.8 & 3.6 & 1.7 & 0.4 & 87.6 \\
\hline $0.06-0.099$ & 0.8 & 2.2 & 1.3 & 0.4 & 4.6 \\
\hline $0.10-0.199$ & 0.8 & 1.8 & 1.9 & 0.7 & 5.2 \\
\hline $0.20+$ & 0.3 & 0.6 & 1.1 & 0.5 & 2.5 \\
\hline Total & 83.7 & 8.3 & 5.9 & 2.1 & 100 \\
\hline
\end{tabular}

moderate to good level of agreement of BAC and clinical assessment for the overall classification table. However, because some of the more desirable properties of the Tau-B measure, as discussed above, only Tau-B will be reported in subsequent analyses.

Table 2 shows values of Tau-B for concordance between the clinical assessment and BAC estimate for the total sample and for those reporting drinking within six hours prior to injury. Levels of concordance or agreement between the two variables were higher for the total sample $(86 \%$ raw agreement; Tau-B 0.68), probably because, in part, of the large proportion of patients who registered $<0.06$ on the breathalyser and who were also clinically assessed as not intoxicated $(82 \%)$. No difference was found by gender for concordance of clinical assessment with estimated BAC. In the total sample, concordance was significantly higher for those with a negative RAPS4 and for those negative on tolerance. The direction of misclassification resulting in this difference was examined and found to be because of a higher rate of clinician over classification (clinicians assessing patients as intoxicated at low BAC levels) for those positive on the RAPS4 and tolerance compared with those negative on these measures. No difference was found for timing of the clinical assessment in relation to the BAC estimate. When concordance was examined for only those patients who reported drinking within six hours prior to injury, no difference was found on dependence or tolerance.

Level of concordance between clinical assessment and BAC was also examined by whether a trained physician (seven sites) or trained nurse (four sites) carried out the assessment, and no difference was found (not shown). In the remaining site, both physicians and nurses were trained to perform the assessment.

Table 3 shows the level of concordance between clinical assessment and BAC for each country by gender and alcohol dependence. Tolerance was not included in this table because the number of those positive across individual studies was too small to provide stable estimates. Level of concordance between the IA and both the clinical assessment and BAC estimate was also examined. In the four countries where an IA was also carried out, concordance of IA was greater with clinical assessment than with BAC estimate. In three of the four countries, IA appeared to be at least as good as clinician assessment.

Pooled effect sizes for concordance were found to be significant across all subgroups, but no significant differences were found within subgroups. However, effect sizes were homogeneous across studies only for females and for those negative on the RAPS4 - the two subgroups with a larger proportion of those negative on the breathalyser and/or negative on clinical assessment.

\section{DISCUSSION}

The concordance of clinical assessment of intoxication with estimated BAC obtained at the time of the ER visit appears to 
Table 2 Agreement between clinical assessment (Y91) and blood alcohol concentration (BAC) (Y90)

\begin{tabular}{|c|c|c|c|c|c|c|}
\hline & \multicolumn{3}{|c|}{ All injury patients } & \multicolumn{3}{|c|}{ Patients drinking 6 hours before injury } \\
\hline & $\mathbf{n}$ & $\begin{array}{l}\text { Raw agreement } \\
(\%)\end{array}$ & Tau-B (SE) & $\mathbf{n}$ & $\begin{array}{l}\text { Raw } \\
\text { agreement (\%) }\end{array}$ & Tau-B (SE) \\
\hline Total & 4798 & 86.4 & $0.679(0.014)$ & 951 & 39.4 & $0.319(0.026)$ \\
\hline Male & 3160 & 82.4 & $0.663(0.015)$ & 802 & 38.9 & $0.312(0.029)$ \\
\hline Female & 1631 & 94.1 & $0.704(0.036)$ & 148 & 42.5 & $0.373(0.062)$ \\
\hline $\begin{array}{l}\text { BAC } 30 \text { min to } 3 \mathrm{~h} \\
\text { before assessment }\end{array}$ & 189 & 85.7 & $0.459(0.096)$ & 38 & 39.5 & $0.154(0.150)$ \\
\hline $\begin{array}{l}\text { BAC 1-30 min } \\
\text { before assessment }\end{array}$ & 254 & 87.4 & $0.754(0.051)$ & 48 & 47.9 & $0.410(0.110)$ \\
\hline $\begin{array}{l}\text { BAC the same time } \\
\text { as assessment }\end{array}$ & 739 & 84.7 & $0.587(0.039)$ & 143 & 27.3 & $0.179(0.068)$ \\
\hline $\begin{array}{l}\text { BAC } 1-30 \text { mins } \\
\text { after assessment }\end{array}$ & 2782 & 86.0 & $0.704(0.017)$ & 566 & 40.8 & $0.336(0.034)$ \\
\hline $\begin{array}{l}\text { BAC } 30 \text { min to } 3 \mathrm{~h} \\
\text { after assessment }\end{array}$ & 243 & 93.0 & $0.683(0.085)$ & 27 & 48.2 & $0.587(0.118)$ \\
\hline Positive RAPS4 & 948 & 66.1 & $0.576(0.023)^{*} \dagger$ & 493 & 39.8 & $0.277(0.038)$ \\
\hline Negative RAPS4 & 3616 & 91.9 & $0.648(0.023)$ & 407 & 39.1 & $0.340(0.038)$ \\
\hline Positive tolerance & 215 & 51.6 & $0.481(0.044)^{\star * *} \ddagger$ & 151 & 32.9 & $0.269(0.065)$ \\
\hline Negative tolerance & 4313 & 88.4 & $0.674(0.016)$ & 725 & 40.3 & $0.332(0.030)$ \\
\hline
\end{tabular}

be high among those not consuming substantial amounts of alcohol prior to the ER visit, with $82 \%$ of the sample with a $\mathrm{BAC}<0.06$ and assessed as not intoxicated.

Agreement was considerably lower (39\%) for those reporting drinking within six hours prior to injury-the group most likely to be intoxicated and/or have a positive BAC at the time of admission to the ER. Nevertheless, only a small per cent of patients were assessed as not intoxicated who had high BACs at the moderately or severely intoxicated level $(1 \%)$, or assessed as moderately or severely intoxicated with negative BACs $(0.5 \%)$. In this latter group, the possibility of other drug involvement was indicated and should be considered in clinical assessment of patients for alcohol intoxication in the ER setting.

Tolerance and/or dependence were found to influence the concordance of clinical assessment with BAC, but not in the direction expected. It was thought that those tolerant to alcohol's effects might be assessed as not intoxicated at relatively high BAC levels. In fact, the opposite was found with these individuals assessed as intoxicated at relatively low levels of BAC. It is possible that those with a history of heavy alcohol consumption (and who would be tolerant) may have a diminished capacity to metabolise alcohol because of alcohol related organ damage resulting in signs and symptoms associated with intoxication at relatively low levels of BAC. An alternative explanation is that those positive on tolerance and/or the RAPS4 would be more likely to have been drinking, and a tendency may have existed on the part of the clinicians to assign some level of intoxication to anyone who appeared to have been drinking.

Surprisingly, other factors that might be thought to affect the concordance of clinical assessment with BAC, such as gender, timing of the assessment in relation to ascertainment of the BAC, or the extent of experience of the individual performing the assessment, were not found to affect agreement between the two measures. Assessment by untrained interviewers appeared to be as good as clinician assessment in three of the four countries in which IA was also evaluated; however, the number of studies is small and this finding should be pursued in future research.

Pooled estimates of concordance between clinical assessment and BAC were homogeneous only for females and those negative on dependence-the two groups most likely to be negative for intoxication and/or BAC at the time of ER admission.

One limitation of this study is the extent and quality of training clinicians may have received in clinical assessment. Although the same set of training materials provided by WHO were used at each study site, training was carried out by a number of different individuals and the extent of similarities and differences in training across sites is unknown.

Based on the study's findings, use of the Y9l codes in the ER appears to be a reasonably valid method of assessing alcohol intoxication, although the level of intoxication appears to be more difficult to assess than whether the patient has consumed any substantial amount of alcohol prior to the ER visit—a result also found in other studies. ${ }^{8}$ Given the busy atmosphere of the ER, a brief clinical assessment would be easier to routinely implement by a variety of personnel in the ER setting than obtaining an actual estimate of the BAC, which would require more time and patient cooperation and may carry legal implications. Y91 codes could supply data for documenting the burden of alcohol related injury in the ER and tracking changes over time, as well as prove useful for patient care management in the ER. Given the variable concordance of clinical assessment with BAC, it would also be prudent to obtain an estimate of BAC in those cases in which patients show an altered level of consciousness.

Clinical procedures in the ER may vary according to whether a patient shows signs of severe intoxication. ${ }^{26}$ Clinical assessment in this regard must have high sensitivity-that is, the ability to detect all of the cases that are in fact severely intoxicated. The implementation of Y91 codes, in this respect, could still be improved-for example, by specific training. Future research should focus on the content and extent of training required for valid assessment, including those factors-for example, drug use-that may influence accuracy of clinical assessment.

Additionally, patients identified as alcohol involved at the time of the ER visit may be potential candidates for a brief intervention to reduce problem drinking. The ER visit has been identified as an opportune time for initiating a brief intervention with these patients; patients for whom a link can be established between their drinking and the reason for 
Table 3 Tau-B and SE of agreement between clinical assessment (Y91), blood alcohol concentration (BAC) (Y90), and interviewer assessment (IA) by country

\begin{tabular}{|c|c|c|c|c|c|c|c|c|c|}
\hline & \multirow[b]{2}{*}{$\mathbf{n}$} & \multicolumn{6}{|l|}{ Y91 v Y90 } & \multirow{2}{*}{$\begin{array}{l}\text { IA } v \text { Y91* } \\
\text { Total }\end{array}$} & \multirow{2}{*}{$\begin{array}{l}\text { IA } v \text { Y90* } \\
\text { Total }\end{array}$} \\
\hline & & Total & 6 hours drinkers & Female & Male & Positive RAPS4 & $\begin{array}{l}\text { Negative } \\
4 \text { RAPS4 }\end{array}$ & & \\
\hline Argentina & 424 & $0.65(0.05)$ & $0.42(0.07)$ & $0.49(0.18)$ & $0.66(0.05)$ & $0.53(0.09)$ & $0.62(0.06)$ & & \\
\hline Belarus & 457 & $0.70(0.03)$ & $0.47(0.06)$ & $0.69(0.08)$ & $0.67(0.04)$ & $0.67(0.05)$ & $0.67(0.06)$ & $0.81(0.03)$ & $0.74(0.03)$ \\
\hline Brazil & 478 & $0.63(0.06)$ & $0.35(0.12)$ & $0.66(0.18)$ & $0.61(0.07)$ & $0.53(0.10)$ & $0.67(0.10)$ & $0.86(0.03)$ & $0.60(0.06)$ \\
\hline Canada & 206 & $0.50(0.31)$ & $0.48(0.34)$ & NA $\ddagger \S$ & $0.71(0.25) \S$ & $0.71(0.25) \S$ & $\mathrm{N} / \mathrm{A} \pm \S$ & & \\
\hline China & 453 & $0.70(0.07)$ & $0.33(0.17)$ & $0.57(0.24)$ & $0.71(0.08)$ & $0.66(0.17)$ & $0.52(0.13)$ & $0.99(0.003)$ & $0.71(0.08)$ \\
\hline Czech Republic & 455 & $0.35(0.13)$ & $0.27(0.18)$ & NA $\pm \S$ & $0.38(0.14) \S$ & $0.35(0.20)$ & $0.32(0.18)$ & & \\
\hline India & 544 & $0.54(0.04)$ & $0.16(0.08)$ & $0.81(0.17)$ & $0.51(0.04)$ & $0.21(0.09)$ & $0.62(0.06)$ & $0.71(0.08) \oplus$ & $0.31(0.11)$ ศ \\
\hline Mexico & 386 & $0.59(0.06)$ & $0.29(0.10)$ & $0.65(0.12)$ & $0.58(0.07)$ & $0.50(0.10)$ & $0.65(0.08)$ & & \\
\hline Mozambique & 445 & $0.72(0.05)$ & $0.30(0.10)$ & $0.58(0.22)$ & $0.71(0.05)$ & $0.71(0.09)$ & $0.69(0.06)$ & & \\
\hline New Zealand $\dagger$ & 119 & $0.68(0.07)$ & $0.34(0.13)$ & $0.83(0.11)$ & $0.65(0.08)$ & & & & \\
\hline South Africa & 454 & $0.72(0.02)$ & $0.44(0.05)$ & $0.79(0.05)$ & $0.70(0.03)$ & $0.55(0.05)$ & $0.69(0.04)$ & & \\
\hline Sweden & 377 & $0.76(0.05)$ & $0.61(0.06)$ & $0.62(0.14)$ & $0.80(0.05)$ & $0.75(0.05)$ & $0.77(0.10)$ & & \\
\hline \multirow{3}{*}{\multicolumn{2}{|c|}{$\begin{array}{l}\text { Test of } \\
\text { homogeneity }\end{array}$}} & $Q=27.3$ & $Q=25.4$ & $Q=6.8$ & $Q=23.9$ & $Q=35.7$ & $Q=7.8$ & & \\
\hline & & $(d f=11)$ & $(d f=11)$ & $(d f=9)$ & $(d f=9)$ & $(d f=9)$ & $(d f=9)$ & & \\
\hline & & $p=0.004$ & $p=0.008$ & $p=0.654$ & $p=0.004$ & $p=0.000$ & $p=0.551$ & & \\
\hline \multirow{2}{*}{\multicolumn{2}{|c|}{$\begin{array}{l}\text { Fixed effect } \\
\text { Random effect }\end{array}$}} & $0.68(0.01)$ & $0.41(0.03)$ & $0.74(0.03)$ & $0.67(0.02)$ & $0.60(0.02)$ & $0.66(0.02)$ & & \\
\hline & & $0.66(0.03)$ & $0.38(0.04)$ & $0.74(0.03)$ & $0.66(0.03)$ & $0.56(0.05)$ & $0.66(0.02)$ & & \\
\hline \multicolumn{10}{|c|}{$\begin{array}{l}\text { *Interviewer assessment was only conducted in Belarus, Brazil, China, and India. } \\
\text { †New Zealand study did not ask RASP4 and tolerance question. } \\
\text { tNot available because distribution of Y90/Y91 has no variability. } \\
\text { \$Excluded from homogeneity test and pooled effect size to have comparable estimates. } \\
\text {-Only } 105 \text { respondents were assessed by interviewer in India study. }\end{array}$} \\
\hline
\end{tabular}

their ER visit may be particularly motivated to change their drinking behaviour. ${ }^{27}{ }^{28}$ The few studies on interventions in the ER have found reductions in future drinking and trauma readmission, ${ }^{28}$ as well as drinking and driving, traffic violations, alcohol related injuries, and alcohol related problems among 18 and 19 year olds. ${ }^{29}$ In order to identify patients who might benefit from a brief intervention in the ER setting, clinical assessment must be relatively inclusive identifying the majority of patients who are alcohol involved. The Y91 measure has been shown to capture this population to a large degree, and Y91 coding may prove important in screening patients to receive brief interventions.

\section{ACKNOWLEDGEMENTS}

This paper is based on the data and experience obtained during the participation of the authors in the WHO Collaborative Study on Alcohol and Injuries, sponsored by the World Health Organization and implemented by the WHO Collaborative Study Group on Alcohol and Injuries, including V Benegal (Bangalore, India); G Borges (Mexico City, Mexico); S Casswell (Auckland, New Zealand); C Cherpitel (Berkeley, USA); M Cremonte (Mar del Plata, Argentina); R Evsegneev (Minsk, Belarus); N Figlie (São Paulo, Brazil); N Giesbrecht (Ontario, Canada); W Hao (Hunan, China); G Humphrey (Auckland, New Zealand); R Larajeira (São Paulo, Brazil); S Macdonald (Ontario, Canada); S Larsson (Malmö, Sweden); S Marais (Cape Town, South Africa); O Neves (Maputo, Mozambique); M Peden (WHO, Geneva, Switzerland); V Poznyak (WHO, Geneva, Switzerland); J Rehm (Zurich, Switzerland); R Room (Stockholm, Sweden); H Sovinova (Prague, Czech Republic); M Stafstrom (Malmö, Sweden). A list of other staff contributing to the project can be found in the Main Report of the Collaborative Study on Alcohol and Injuries, WHO, Geneva.

\section{Authors' affiliations}

C Cherpitel, J Bond, Y Ye, Alcohol Research Group, Berkeley, USA

R Room, Stockholm University, Sweden

V Poznyak, M Peden, World Health Organization

J Rehm, Center for Addiction and Mental Health, Ontario, Canada

Preparation of this paper was supported in part by a grant from the US National Institute on Alcohol Abuse and Alcoholism (RO1 AA1375002).

Competing interests: none declared
The authors alone are responsible for views expressed in this paper, which do not necessarily represent those of the other investigators participating in the WHO Collaborative Study on Alcohol and Injuries nor the views or policy of the World Health Organization.

This paper was presented at the Research Society for Alcoholism Annual Meeting, Vancouver, British Columbia, Canada, June 26 to July 1, 2004.

A research report from the WHO Collaborative Study on Alcohol and Injuries.

\section{REFERENCES}

1 Ezzati M, Lopez AD, Rodgers A, et al. Selected major risk factors and global and regional burden of disease. Lancet 2002;360(9343): 1347-60.

2 Rehm J, Rehn N, Room R, et al. The global distribution of average volume of alcohol consumption and patterns of drinking. Eur Addict Res 2003;9(4): 147-56.

3 World Health Organization. International Classification of Diseases Ninth revised. ed. Geneva, Switzerland: World Health Organization, 1977.

4 Room R. Notes on alcohol in the Ninth International Classification of Diseases. Berkeley, CA: Alcohol Research Group, 1982.

5 Grant B, Dufour M, Stinson F, et al. Proposed coding of alcohol's role in casualties. Alcohol Health Res World 1987;12:48-50.

6 World Health Organization. The ICD-10 Classification of Mental and Behavioural Disorders. Clinical descriptions and diagnostic guidelines. Geneva, Switzerland: World Health Organization, 1992.

7 MacAndrew C, Edgerton RB. Drunken comportment: A social explanation. Chicago. Aldine Publishing Co, 1969

8 Honkanen R. Records based on clinical examination as an indicator of alcohol involvement in injuries at emergency stations. Scand J Soc Med 1977;5:91-5.

9 Honkanen R, Ottelin J. Blood alcohol levels in injury victims at the emergency station of a rural central hospital. Ann Chir Gynaecol 1976;65:282-6.

10 Cherpitel CJ. Alcohol and injuries: A review of international emergency room studies. Addiction 1993;88:923-7.

11 Gibb K, Yee A, Johnson C, et al. Accuracy and usefulness of a breath alcohol analyzer. Ann Emerg Med 1984;13:516-20.

12 Cherpitel CJ. A brief screening instrument for problem drinking in the emergency room: the RAPS4. J Stud Alcohol 2000;61:447-9.

13 Cherpitel CJ. Screening for alcohol problems in the emergency room: A rapid alcohol problems screen. Drug Alcohol Depend 1995:40:133-7.

14 American Psychiatric Association. Diagnostic and Statistical Manual of Mental Disorders, Text Revision [DSM-IV-TR]. 4th ed. Washington, DC: American Psychiatric Association, 2000.

15 World Health Organization. ICD-10: International Statistical Classification of Diseases and Related Health Problems Tenth revised, ed. Geneva, Switzerland: World Health Organization, 1992.

16 Cherpitel CJ. Differences in performance of screening instruments for problem drinking among blacks, whites and hispanics in an emergency room population. J Stud Alcohol 1998;59:420-6.

17 Cherpitel CJ, Bazargan S. Screening for alcohol problems: comparison of the audit, RAPS4, and RAPS4-QF among African American and Hispanic patients in an inner city emergency department. Drug Alcohol Depend 2003;71:275-80. 
18 Cherpitel CJ, Borges G. Performance of screening instruments for alcohol problems in the ER: a comparison of Mexican-Americans and Mexicans in Mexico. Am J Drug Alcohol Abuse 2000;26(4):683-702.

19 Jones AW, Pounder DJ. Measuring blood-alcohol concentration for clinical and forensic purposes. In: Karch SG, ed. Drug Abuse Handbook. Boca Raton, FL: CRC Press, 1998:327-56.

20 Schuckit MA. Drug and alcohol abuse. A clinical guide to diagnosis and treatment, 4th ed. New York: Plenum Medical Book Company, 1995.

21 Kruskal WH. Ordinal measures of association. J Am Stat Assoc 1958:53:814-61.

22 Cook RJ. Kappa and its dependence on marginal rates. In: Armitage P, Colton T, eds. Encyclopedia of Biostatistics. New York, NY: John Wiley \& Sons, 1988:2166-8.

23 Agresti A. The effect of category choice on some ordinal measure of association. J Am Stat Assoc 1976:71:49-55.

24 Hedges LV, Olkin I. Statistical methods for meta-analysis. Orlando, FL: Academic Press, Inc, 1985.

25 Sutton AJ, Abrams KR, Jones DR, et al. Methods for meta-analysis in medical research. Chichester, UK: John Wiley and Sons, 2000.

26 Carrigan TD, HF, Illingworth RN, et al. Toxicological screening in trauma. $J$ Accid Emerg Med 2000;17(1):33-7.

27 DiClemente CC, Bellino LE, Neavins TM. Motivation for change and alcoholism treatment. Alcohol Res Health 1999;23(2):86-92.

28 Gentilello LM, Rivara FP, Donovan DM et al. Alcohol interventions in a trauma center as a means of reducing the risk of injury recurrence. Ann Surg 1999;230(4):473-80

29 Monti PM, Colby SM, Barnett NP, et al. Brief intervention for harm reduction with alcohol-positive older adolescents in a hospital emergency department. J Consult Clin Psychol 1999:67(6):989-94.

\section{APPENDIX B}

Interviewer assessment (IA) of alcohol intoxication

Based on your observation and descriptions given below please circle an appropriate figure in the right column

It is impossible to establish a meaningful communication with a person. It is unclear whether a person is uncooperative (soporose/comatose) because of alcohol intoxication or other medical condition, or both.

It is obvious that a person is severely intoxicated even without any interaction with him/her. It is possible to establish communication with a person, though communication and interaction are severely impaired because of intoxication.

It is obvious that a person is intoxicated if interacting with him/her or when performing coordination demanding tasks. However, alcohol intoxication is not obvious for other people without interaction or performance of coordination demanding tasks.

This person is intoxicated, but it is not obvious for other people even if interacting with him/her.

Alcohol involvement, not otherwise specified Please specify reason:

Not intoxicated at all

\section{APPENDIX A}

Clinical assessment of alcohol intoxication

\begin{tabular}{llllll}
\hline & \multicolumn{3}{l}{ Severity/prominence } \\
\cline { 2 - 4 } Clinical signs & $\begin{array}{l}\text { Very } \\
\text { severe }\end{array} \quad$ Severe & Moderate & Mild & None & $\begin{array}{l}\text { Not applicable } \\
\text { (specify) }\end{array}$ \\
\hline
\end{tabular}

Smell of alcohol on breath

Conjunctival injection and/or flushed face

Impairment of speech-for example,

slurring

Impairment of motor coordination

Impairment of attention and/or judgement

Elated (euphoria) or depressed mood

Disturbances in behavioural responses

Disturbances in emotional responses

Impaired ability to cooperate

Horizontal gaze nystagmus

Y91 Based on the signs above, would you say that the patient is in the state of: (Tick appropriate box)

Y91.3 Very severe alcohol intoxication

(Very severe disturbance in functions and responses, very severe difficulty in coordination, or loss of ability to cooperate)

Y91.2 Severe alcohol intoxication

(Severe disturbance in functions and responses, severe difficulty in coordination, or impaired ability to cooperate)

Y91.1 Moderate alcohol intoxication

(Smell of alcohol on breath, moderate behavioural disturbance in functions and responses, or moderate difficulty in coordination)

Y91.0 Mild alcohol intoxication

(Smell of alcohol on breath, slight behavioural disturbance in functions and responses, or slight difficulty in coordination)

Y91.9 Alcohol involvement, not otherwise specified Please specify reason:

Not intoxicated at all

Do you think that there is any evidence of substance usage other than alcohol? No

Yes, based on self report

Yes, based on collateral information

Yes, based on self report and collateral information

Not sure 
Clinical assessment compared with breathalyser readings

\section{Clinical assessment compared with breathalyser readings in the ER: concordance of ICD-10 Y90 and Y91 codes}

\section{R Touquet}

C linical assessment of the amount of alcohol that has been consumed by a patient presenting to the emergency department is notoriously difficult. How should the caring professions respond to the "Epidemic of Binge Drinking in the United Kingdom (UK) $)^{\prime \prime} ?^{1}$ Alcohol is a drug like any other, which depresses inhibitions initially, but is legal and used by $90 \%$ of society, including the medical profession. ${ }^{2}$

This paper, a work from twelve countries, defines the accuracy of clinical assessment (ICD-10 Y91) by comparison with alcohol breathalyser readings (ICD-10 Y90). It is well worked, multinational, with robust methodologies supported by the World Health Organization (WHO).

The paper shows that approximately $95 \%$ of patients, with blood alcohol concentrations (BAC-as measured by breathalyser) below $60 \mathrm{mg}$ per $100 \mathrm{ml}$ of blood, were correctly diagnosed as being not intoxicated. Approximately $85 \%$ of patients with BAC above $60 \mathrm{mg} \%$ were correctly assessed as being intoxicated. However, there was a low incidence of alcohol intake in this population of 4798 patients; approximately $80 \%$ had not been drinking alcohol within six hours of attending the emergency room.

The measurement instrument RAPS4 - developed from optimal items across several screening instruments, including the well known CAGE questionnaire-does effectively detect dependency.

This paper, therefore, really confirms what we all suspect: that clinical assessment is difficult and for it to be of use clinicians need training.

So how does this paper affect our own practices in the UK? Training in the detection and management of alcohol misuse is judged as important, ${ }^{2}$ and this paper from Cherpitel et al emphasises this need. Emergency department staff, who may be inexperienced, need to be able to make pragmatic, prompt management decisions. The key question is "Is the patient a hazardous drinker who warrants referral for brief intervention with an alcohol health worker (AHW)" $)^{\prime 3-5}$ as opposed to "Is the patient intoxicated at presentation to the accident and emergency department"?

The ICD-10 classifications do not answer this-hence their limitation.

If a patient is alert and orientated, then detecting hazardous drinking by questionnaire is effective. Use of breathalysers is perceived as judgemental causing resentment.

Patients, not alert and orientated, warrant blood alcohol levels to help clinical decision making, ${ }^{6-8}$ and to flag up possible alcohol misuse for later definition with questionnaire-for example, the Paddington Alcohol Test.

Cherpitel et al contribute to the literature by highlighting the need for accident and emergency department staff to be trained in assessing patients for possible alcohol misuse, and, further, that the WHO has no coding for the binge or dependent drinker. Such detection should trigger the offer of referral to the AHW, thereby making maximum use of the "teachable moment".

Alcohol abuse remains a major challenge in our everyday practice and the time has come to move from the reactive approach of dealing with the immediate problem to referring patients for proactive management of problem drinking. We have a long way to go before the recommendation from the Royal College of Physicians, that every acute trust must have their own AHW, ${ }^{9}$ is met.

Emerg Med J 2005;22:695.

doi: $10.1136 / \mathrm{emi} .2004 .022244$

Correspondence to: Professor R Touquet, A \& E Department, St Mary's Hospital, Praed Street, London, W2 1NY; robin.touquet@stmarys.nhs.uk

Accepted for publication 15 November 2004

\section{REFERENCES}

1 Cabinet Office. Prime Minister's Strategy Unit. Alcohol harm reduction strategy for England. London: Cabinet Office, March, 2004.

2 Huntley JS, Patton R, Touquet R. Attitudes towards alcohol of emergency department doctors trained in the detection of alcohol misuse. Ann R Coll Surg Engl 2004;86:329-33.

3 Crawford MJ, Patton R, Touquet R, et al. Screening and referral for brief intervention of alcohol misusing patients in an accident and emergency department: a pragmatic randomized controlled trial. Lancet 2004;364:1334-9.

4 Patton R, Crawford, Touquet R. Hazardous drinkers in the accident and emergency department-who accepts advice? Emerg Med J 2004:21:491-2.

5 Williams S, Brown A, Patton R, et al. The half-life of the 'teachable moment' for alcohol misusing patients in the emergency department. Drug and Alcohol Dependence http://dx.doi.org/ 10.1016/i.drugalcdep.2004.07.011 (accessed 1 August 2005).

6 Peppiatt R, Evans R, Jordan P. Blood alcohol concentrations of patients attending an accident and emergency department. Resuscitation 1978;6:37-43

7 Urso T, Gavaler JS, Van Thiel DH. Blood ethanol levels in 'sober' alcohol users seen in an emergency room. Life Sciences 1981;28:1053-6.

8 Savola O, Niemela O, Hillbom M. Blood alcohol is the best indicator of hazardous alcohol drinking in young adults and working-age patients with trauma. Alcohol 2004;39:340-5.

9 Royal College of Physicians. Alcohol - can the NHS afford it? London: Royal College of Physicians, 2001 